\title{
Prognostic Role of Procalcitonin in Patients with Fever and Respiratory Complains During the COVID-19 Pandemic
}

\author{
Peiman Nazerian ${ }^{1}$ (D) $\cdot$ Manfredi Gagliano $^{1} \cdot$ Alessandra Fanelli $^{2} \cdot$ Stefano $_{\text {Grifoni }}{ }^{1}$
}

Accepted: 11 March 2021 / Published online: 23 March 2021

(C) The Author(s), under exclusive licence to Springer Nature Switzerland AG 2021

Dear Editor,

Procalcitonin (PCT) is currently used in clinical practice to distinguish viral from bacterial infections, to guide antibiotic therapy, and to prognosticate bacterial sepsis or pneumonia [1]. Recent articles showed a prognostic role of PCT in patients with coronavirus disease 2019 (COVID-19), suggesting that PCT is a useful prognostic marker also in this viral infection $[2,3]$. During the pandemic period, patients presenting to the emergency department (ED) with fever and respiratory complains are suspected of COVID-19 [4]. Laboratory test panels for suspected COVID-19 (COVID-19 panel) can help clinician not only for diagnosis but also for patients' prognostication. In our ED, during the COVID-19 pandemic, we included PCT in the COVID-19 panel. The aim of this prospective, observational study was to evaluate if a PCT $\geq 0.5 \mathrm{ng} /$ $\mathrm{mL}$, the cut-off currently used to diagnose bacterial infection, predicts hospital admission and death in patients with fever or respiratory complains irrespective from etiology.

Consecutive patients presenting to the ED from the 18th to the 27th of April 2020 were considered for the study. Inclusion criteria were referred fever or body temperature $>37.5^{\circ} \mathrm{C}$, respiratory symptoms or signs (dyspnoea, cough, pharyngitis, oxygen saturation $\leq 94 \%$ in room air, respiratory rate $\geq 20$ per minute), or need of oxygen administration or ventilation. The COVID-19 panel (including PCT) and reverse-transcriptionpolymerase chain reaction (RT-PCR) tests were performed in all enrolled patients. PCT was measured using an automated ElectroChemiLuminescent immunoassay (ECLIA Elecsys B.R.A.H.M.S. $\mathrm{PCT}^{\mathrm{TM}}$ ). Patients underwent a 30-day follow-

Peiman Nazerian

pnazerian@hotmail.com

1 Department of Emergency Medicine, Careggi University Hospital, largo Brambilla 3, 50134 Firenze, Italy

2 Department of General Laboratory, Careggi University Hospital, Firenze, Italy up and the prognostic role of a PCT $\geq 0.5 \mathrm{ng} / \mathrm{mL}$ was evaluated in all patients considering the following outcomes: hospital admission, intensive care unit (ICU) admission, and death. The same outcomes were evaluated also for the subgroup of patients with a final diagnosis of "COVID-19 pneumonia," "infection not COVID-19 related," and "non-COVID-19 pneumonia". The final diagnosis was established by two expert physicians, one internal medicine specialist with 20 years of medical experience and one emergency medicine specialist with 13 years of medical experience. The experts, blinded to PCT result, independently assessed for each patient's ED, hospital and 30day follow-up clinical data comprehensive of RT-PCR tests performed in any naso-pharyngeal swab and bronchoalveolar lavage and all diagnostic imaging tests. The experts establish if pneumonia was present based on abnormal findings on chest computed tomography or chest X-ray imaging. The "COVID19 pneumonia" group included patients with a diagnosis of pneumonia and at least one positive RT-PCR test, the "infection not COVID-19 related" group included patients with a diagnosis of any type of infection (e.g., sepsis, urinary tract infection, intra-abdominal infection) and negative RT-PCR tests, and the "non-COVID-19 pneumonia" group included patients with a diagnosis of pneumonia and negative RT-PCR tests. In case of discordant adjudication, a third expert specialized in internal medicine and pulmonary medicine with 35 years of medical experience adjudicated the final diagnosis.

Patients enrolled in the study were 213. Considering all included patients presenting with fever and respiratory complains, hospital admissions, ICU admissions, and mortality were significantly higher in patients with PCT $\geq 0.5 \mathrm{ng} / \mathrm{mL}$ (Table 1). Odds ratios of a PCT $\geq 0.5 \mathrm{ng} / \mathrm{mL}$ for hospital admission and death were 8.1 (95\% confidence interval, CI 2.8-23.6) and 5.5 (95\% CI 2.2-13.7) respectively while for ICU admission among patients admitted to hospital was 2.1 (95\% CI 0.7-7). In the group of patients with "infection non-COVID-19 related," those with PCT $\geq 0.5 \mathrm{ng} / \mathrm{mL}$ were hospitalized more frequently than patients with PCT $<0.5 \mathrm{ng} / \mathrm{mL}$ and in the group of patients with "non-COVID-19 pneumonia," deaths occurred more frequently 
Table 1 Thirty-day outcomes

\begin{tabular}{|c|c|c|c|c|}
\hline All patients & $n=213(\%)$ & $\mathrm{PCT} \geq 0.5 \mathrm{ng} / \mathrm{mL} n=53(\%)$ & $\mathrm{PCT}<0.5 \mathrm{ng} / \mathrm{mL} n=160(\%)$ & $p$ value \\
\hline Hospital admissions & $144(67.6)$ & $48(90.6 \%)$ & $96(60 \%)$ & $<0.01^{*}$ \\
\hline ICU admissions & $12(5.6 \%)$ & $6(11.3 \%)$ & $6(3.8 \%)$ & $0.04 *$ \\
\hline Deaths & $22(10.3 \%)$ & $13(24.5 \%)$ & $9(5.6 \%)$ & $<0.01^{*}$ \\
\hline COVID-19 pneumonia & $n=32(\%)$ & $\mathrm{PCT} \geq 0.5 \mathrm{ng} / \mathrm{mL} n=9(\%)$ & $\mathrm{PCT}<0.5 \mathrm{ng} / \mathrm{mL} n=23(\%)$ & $p$ value \\
\hline Hospital admissions & $30(93.8 \%)$ & $9(100 \%)$ & $21(91.3 \%)$ & 0.37 \\
\hline ICU admissions & $5(15.6 \%)$ & $3(33.3 \%)$ & $2(8.7 \%)$ & 0.09 \\
\hline Deaths & $7(21.9 \%)$ & $4(44.4 \%)$ & $3(13 \%)$ & 0.06 \\
\hline Infection non-COVID-19 related & $n=45(\%)$ & $\mathrm{PCT} \geq 0.5 \mathrm{ng} / \mathrm{mL} n=16(\%)$ & $\mathrm{PCT}<0.5 \mathrm{ng} / \mathrm{mL} n=29(\%)$ & $p$ value \\
\hline Hospital admissions & $26(57.8 \%)$ & $13(81.3 \%)$ & $13(44.8 \%)$ & $0.02 *$ \\
\hline ICU admissions & $2(4.4 \%)$ & $2(6.9 \%)$ & 0 & 0.2 \\
\hline Deaths & $3(6.7 \%)$ & $2(12.5 \%)$ & $1(3.4 \%)$ & 0.28 \\
\hline Non-COVID-19 pneumonia & $n=28(\%)$ & $\mathrm{PCT} \geq 0.5 \mathrm{ng} / \mathrm{mL} n=12(\%)$ & $\mathrm{PCT}<0.5 \mathrm{ng} / \mathrm{mL} n=16(\%)$ & $p$ value \\
\hline Hospital admissions & $23(82.1 \%)$ & $11(91.7 \%)$ & $12(75 \%)$ & 0.26 \\
\hline ICU admissions & $2(7.1 \%)$ & $2(16.7 \%)$ & 0 & 0.1 \\
\hline Deaths & $6(21.4 \%)$ & $5(41.7 \%)$ & $1(6.3 \%)$ & $0.03 *$ \\
\hline
\end{tabular}

Values are reported as absolute number and percent value within column in brackets

$P C T$ procalcitonin; $I C U$ intensive care unit

$* p<0.05$

in patients with $\mathrm{PCT} \geq 0.5 \mathrm{ng} / \mathrm{mL}$ (Table 1). As in the other subgroups, in patients with COVID-19 pneumonia, all outcomes were more frequent in patients with PCT $\geq 0.5 \mathrm{ng} / \mathrm{mL}$ but without reaching statistical significance probably because of small sample size (Table 1). Only one patient received a final diagnosis of COVID-19 pneumonia with a proved bacterial coinfection.

In conclusion, in this pilot study, PCT showed to be a prognostic marker in patients presenting with fever or respiratory complains during the COVID-19 pandemic independently from etiology and in patients with a PCT $\geq 0.5 \mathrm{ng} / \mathrm{mL}$, the rate of hospital admissions, ICU admissions, and 30-day mortality was significantly higher.

Acknowledgements List of the "ED COVID-19" investigators: Lorenzo Roberto Suardi, Luisa Lanzilao, Eleonora de Villa, Gabriele Cerini, Enrico Lumini, Alessio Prota, Gian Maria Rossolini, Simona Gualtieri, Barbara Casanova, Elisabetta Catini, Sara Mucaj, Antonio Annovi, Marco Albanesi, Edoardo Cavigli, Chiara Moroni, Vittorio Miele, Fillippo Lagi, Lucia Turco, Matteo Tomaiuolo, Diana Paolini, and Barbara Tonietti.

Availability of Data and Material All data supporting this manuscript are available upon request to the corresponding author.

Code Availability Not applicable.

Author's Contribution P.N. and M.G. designed the study. M.G. and A.F. conducted the study and collected data. P.N. and M.G. analyzed the data. P.N., M.G., A.F, and S.G. gave support in the conduction of the study and revised the manuscript for important intellectual content. P.N. drafted the manuscript.

\section{Declarations}

Ethics Approval The Tuscany Ethical Committee of Area Vasta Centro approved the study $\left(\mathrm{N}^{\circ} 17104\right)$. All procedures performed in studies involving human participants were in accordance with the ethical standards of the institutional and/or national research committee and with the 1964 Helsinki declaration and its later amendments or comparable ethical standards.

Consent to Participate Informed consent was obtained from all individual participants included in the study.

Consent for Publication Not applicable.

Conflict of Interest The authors declare no competing interests.

\section{References}

1. Schuetz P, Albrich W, Mueller B. Procalcitonin for diagnosis of infection and guide to antibiotic decisions: past, present and future. BMC Med. 2011;9:107.

2. Vanhomwegen C, Veliziotis I, Malinverni S, Konopnicki D, Dechamps $\mathrm{P}$, Claus M, et al. Procalcitonin accurately predicts mortality but not bacterial infection in COVID-19 patients admitted to intensive care unit. Ir J Med Sci. 2021. https://doi.org/10.1007/s11845-020-02485-z.

3. Hu R, Han C, Pei S, Yin M, Chen X. Procalcitonin levels in COVID19 patients. Int J Antimicrob Agents. 2020;56(2).

4. Carpenter RC, Mudd AP, West CP, Wilber E, Wilber ST. Diagnosing COVID-19 in the emergency department: a scoping review of clinical examinations, laboratory tests, imaging accuracy, and biases. Acad Emerg Med. 2020. https://doi.org/10.1111/acem.14048.

Publisher's Note Springer Nature remains neutral with regard to jurisdictional claims in published maps and institutional affiliations. 